J Clin Child Adolesc Psychol Vol. 34 (1): 74-86 (2005)

ISSN: (print 1537-4416)(online 1537-4424)

doi: 10.1207/s15374424jccp3401_7

This is a peer reviewed pre-print version of the following article: Peer-Assessed Outcomes in the Multimodal

Treatment Study of Children with Attention Deficit Hyperactivity Disorder, which has been published in final form at:

http://www.routledge.com

http://www.tandfonline.com/toc/hcap20/current

http://www.tandfonline.com/doi/abs/10.1207/s15374424jccp3401_7

(c) 2005 Lawrence Erlbaum Associates, Inc.

\title{
Peer-Assessed Outcomes in the Multimodal Treatment Study of Children With Attention Deficit Hyperactivity Disorder
}

\author{
Betsy Hoza, Alyson C. Gerdes, Sylvie Mrug, Stephen P. Hinshaw, William M. \\ Bukowski, Joel A. Gold, L. Eugene Arnold, Howard B. Abikoff, C. Keith Conners, \\ Glen R. Elliott, Laurence L. Greenhill, Lily Hechtman, Peter S. Jensen, Helena C. \\ Kraemer, John S. March, Jeffrey H. Newcorn, Joanne B. Severe, James M. \\ Swanson, Benedetto Vitiello, Karen C. Wells, and Timothy Wigal
}

Abstract

Peer-assessed outcomes were examined at the end of treatment (14 months after study entry) for 285 children (226 boys, 59 girls) with attention deficit hyperactivity disorder (ADHD) who were rated by their classmates (2,232 classmates total) using peer sociometric procedures. All children with ADHD were participants in the Multimodal Treatment Study of Children with ADHD (MTA). Treatment groups were compared using the orthogonal treatment contrasts that accounted for the largest amount of variance in prior MTA outcome analyses: Medication Management + Combined Treatment versus Behavior Therapy + Community Care; Medication Management versus Combined Treatment; Behavior Therapy versus Community Care. There was little evidence of superiority of any of the treatments for the peer-assessed outcomes studied, although the limited evidence that emerged favored treatments involving medication management. Post hoc analyses were used to examine whether any of the four treatment groups yielded normalized peer relationships relative to randomly selected- classmates. Results indicated that children from all groups remained significantly impaired in their peer relationships.

Despite the widely accepted premise that children with attention deficit hyperactivity disorder (ADHD) have problematic peer relationships, the mechanisms underlying these peer difficulties remain poorly understood. Deficits in social skills knowledge, performance, and selfcontrol all have been postulated as important factors (for reviews, see Mrug, Hoza, \& Gerdes, 2001; Wheeler \& Carlson, 1994). Whereas earlier studies (e.g., Cunningham, Siegel, \& Offord, 1985) suggested that inattentiveness may be a factor limiting opportunities for observational learning of social skills in children with ADHD, more recent work focuses on performance deficits (Barkley, 2000). Further, it is now widely accepted that a major contributing factor to the peer problems of children with ADHD is their largely unrestrained, overbearing interaction style, characterized by hyperactivity, aggression, bossiness, and other forms of controlling behavior that make them highly aversive to peers (see Mrug et al., 2001; Whalen \& Henker, 1992, for reviews).

Stimulant medication is useful for reducing rates of these negative and controlling behaviors (Cunningham et al., 1985) but typically yields few corresponding increases in positive behaviors (see Landau \& Moore, 1991, and Whalen \& Henker, 1991, for reviews). Nonetheless, laboratory studies requiring normal peers to rate videotaped behavior of children with ADHD in both medicated and unmedicated states suggest that medication-related improvements in 
behavior are quite apparent to nondeviant peers even after short periods of observation (e.g., 15 min; Whalen, Henker, Castro, \& Granger, 1987). Such findings suggest that medication may be an important part of any intervention for the peer problems of children with ADHD but that additional interventions are needed.

Most psychological interventions for childhood peer problems are based on the social skills deficit model of peer rejection (e.g., Oden \& Asher, 1977). This model attributes peer rejection to social skills knowledge or performance deficits and posits that teaching social skills to the poorly accepted child will result in amelioration of peer problems. Results of social skills training studies, mostly conducted with nonclinical or school samples, have been very mixed, especially for children with externalizing symptoms. Better results are seen when social skills training is coupled with behavioral programs targeting negative behaviors or reinforcing use of social skills (Bierman, Miller, \& Stabb, 1987; Pelham \& Bender, 1982; Pfiffner \& McBurnett, 1997; see Landau and Moore, 1991, for a review), but generalization of gains beyond the treatment setting is rarely achieved (see Pfiffner \& McBurnett, 1997, for a study showing modest generalization over a short time period). Taken together, these results suggest that an effective intervention for the peer problems of children with ADHD may need to target skill and performance deficits through psychosocial interventions, address behavioral excesses via medication, and also attend to issues of generalization.

Other authors, however, point to different factors in explaining the etiology of peer and other social problems of children with ADHD. Barkley (2000), based on his earlier theory of ADHD (for a succinct summary, see Barkley, 1998) argued, "Instead, these problems can just as easily arise from faulty development in critical cognitive abilities that underlie the performance of these skills, from motivational deficits underlying persistence of their performance, or from a defective mental time horizon over which the individual is contemplating his responses, among other origins” (p. 597). Fortunately, as we have discussed elsewhere (Swanson et al., 2002), even this alternative perspective regarding etiology does not yield vastly different treatment recommendations.

The rather modest results of intervention studies to date targeting externalizing children's peer problems should be of concern for several reasons. First, peer problems in general are widely known to be predictive of a range of serious adjustment problems over time, including delinquency, substance abuse, school dropout, academic difficulties, and development of other psychopathology (for reviews, see Parker \& Asher, 1987; Rubin, Bukowski, \& Parker, 1998). In addition, follow-up studies of children with ADHD have shown them to be at elevated risk for similar adverse outcomes such as antisocial behavior (Satterfield, Swanson, Schell, \& Lee, 1994), academic and occupational impairments and school dropout (Barkley, 1998), elevated rates of driving accidents (Barkley, Guevremont, Anastopoulos, DuPaul, \& Shelton, 1993), and social problems (Weiss \& Hechtman, 1993).

Given the established risks associated with having either peer problems or ADHD, it stands to reason that children who have both ADHD and significant peer problems in childhood may face particularly negative outcomes over time, although, surprisingly, this remains to be investigated. For these reasons, it is imperative to place a high priority on remediating the peer difficulties of children with ADHD. Despite this pressing need, the literature on intervention for peer problems of clinically diagnosed children with ADHD remains sparse and unimpressive. Notable limitations include the following: (a) the short-term nature of interventions applied to these problems, even though ADHD is now known to be a chronic disorder; (b) the tendency for researchers to study primarily school samples of children with externalizing symptoms without 
applying current diagnostic criteria; and (c) a limited range of outcome measures that do not actually consider peers' perspectives. Each of these limitations is discussed in the following.

The problems inherent in applying a short-term intervention to a lifelong, chronic disorder are obvious. Indeed, the need to study effective treatments for ADHD over a longer time interval formed part of the underlying rationale for the Multimodal Treatment Study of Children with ADHD (MTA; Richters et al., 1995). Prior to the MTA, most treatment studies applied to ADHD were of short-term duration, usually a few months or less (for exceptions, see Klein, Abikoff, Hechtman, \& Weiss, 2004; Satterfield, Satterfield, \& Schell, 1987). Further, many, if not most of these short-term interventions were not specifically geared toward the peer problems of children with ADHD. More recently, even when such components were included in interventions, they were similarly short term (e.g., Hoza, Mrug, Pelham, Greiner, \& Gnagy, 2003; Pelham \& Hoza, 1996; Pfiffner \& McBurnett, 1997). Given the long-term predictive value of peer problems for later adjustment, however, it seems that a sustained focus on peer problems is warranted.

Although there is a prolific literature on peer problems of children with externalizing symptoms, the value of this literature in understanding peer problems of children with specific disorders such as ADHD is limited. School-recruited samples are typically employed, and results from these studies cannot be viably generalized to clinically diagnosed children. According to the current diagnostic system, the age of onset criterion and the documentation of impairment in two or more settings are critical to the identification of ADHD (American Psychiatric Association, 1994), yet this type of information is rarely available on school samples.

Finally, peer sociometric measures have only rarely been used as outcome measures in intervention studies employing children with ADHD. Our own perusal of the literature yielded only a few studies (Pelham \& Bender, 1982; Pelham et al., 1988; Whalen et al., 1989). Although important work has been accomplished using peer sociometric methods to describe the peer problems of children with ADHD (Hoza et al., in press; for a review, see Mrug et al., 2001), it is a completely different task to demonstrate that our interventions can normalize social status with peers. Notably, a recent review of social skills training as a treatment for aggressive children concluded that an inability to alter peer status plagues the social skills literature generally (Nangle, Erdley, Carpenter, \& Newman, 2002).

If peer status is highly resistant to change, it stands to reason that indexes of treatment outcome should include peer-assessed measures that directly reflect peers' perspectives. As noted by Foster, Inderbitzen, and Nangle (1993), such measures "indicate the social validity of behavior changes produced by intervention by assessing whether such changes were associated with improved acceptance by peers” (pp. 275-276). In other words, although peer-assessed measures may not indicate whether particular skills were acquired, they accurately reflect peers' current perspectives regarding the target child. Given the strong predictive utility of peer report for later outcomes (for a review, see Rubin et al., 1998), greater emphasis on measures that utilize peer report seems critical.

One reason that an extensive study of the interplay between peer problems and clinically diagnosed externalizing disorders has not been previously conducted is the expense, both in monetary cost and labor intensity, of providing research diagnoses on a large sample of children and collecting data from each child's entire classroom of peers. However, at three time points, the MTA (for a description, see Arnold et al., 1997) collected sociometrics on a subgroup of their sample. The primary analyses for the MTA at 14 months have been published elsewhere (MTA Cooperative Group, 1999a, 1999b), involving comparisons of the three MTA-treated groups 
(medication management, behavior therapy, combined treatment) to each other, and each to the community care group. All four groups improved over time, but relative improvements varied somewhat by domain of functioning. Medication management and combined treatment were both significantly superior to behavior therapy and community care in terms of reducing ADHD symptoms. For comorbid conditions extending beyond ADHD symptomatology (oppositional or aggressive, internalizing symptoms) and functional outcomes (social skills, parent-child relationships, and academic functioning), combined treatment was the only condition that was consistently superior to community care (MTA Cooperative Group, 1999a).

In the initial outcome articles from the MTA, peer-assessed outcomes were not emphasized. ${ }^{\mathrm{i}}$ Our goal in this article, therefore, is to examine how the four treatment groups from the MTA compared in terms of alleviating the peer problems of children with ADHD, using peer-assessed outcome measures. Based on the previously described limitations of both psychosocial therapies and stimulant medication when used alone in addressing the peer problems of children with ADHD, we predicted that combined treatment would show the most promising results - that is, would come closest to bringing scores into the normal range. Further, we hypothesized that stimulant medication would prove to be a critical component of treatment for the peer problems of children with ADHD, given its documented effectiveness at reducing disruptiveness and aversive interchanges between children with ADHD and their peers (see Whalen \& Henker, 1991).

\section{Method}

Overview of MTA Treatments and Sociometric Assessments

Behavioral treatment families received 27 group and 8 individual behavioral parent training sessions; an 8-week, 45-hr per week summer treatment program (Pelham \& Hoza, 1996); and a school intervention that included 10 to 16 sessions of teacher consultation and 12 weeks of a half-time behaviorally trained paraprofessional aide (see Wells et al., 2000, for a complete description). The summer treatment program included daily social skills training, a dyadic friendship intervention, performance of cooperative tasks with peers, and anger management and problem-solving training, all geared at improved functioning with peers. These peer-oriented components were implemented within the context of a highly structured behavioral point system.

Children assigned to the medication management group underwent a 28-day double-blind placebo-controlled titration to determine the child's optimal medication dose. This titration was followed by monthly medication management visits and monthly contact with the child's teacher to assist the pharmacotherapist in making dose adjustments (see Greenhill et al., 1996, for a comprehensive description). Combined treatment involved all medication and behavioral components of treatment, administered in a coordinated, algorithm-driven manner, with regular contact among treatment providers. Community care families were assessed by MTA staff, given a report summarizing their assessment, and thereafter were free to choose their own treatments in the community at their own expense.

A large battery of assessment instruments was administered to families participating in the MTA at fixed intervals, as described in Hinshaw at al. (1997). Peer sociometric measures were administered at three of these times: baseline, 14 months, and 24 months, although they were optional (and only three of the six sites opted to collect them) at baseline. All sites attempted to provide 14-month (end of treatment) and 24-month data, but several factors prevented collection of sociometrics for all MTA participants. These factors included school or 
teacher refusal, school no longer being in session, classmates not returning permission slips, and staffing limitations. Data on the exact number of children excluded for each of these reasons were not collected, but primary reasons were school refusal and staffing limitations. Regarding school refusal, even though each child's school at protocol entry consented to the full protocol, by 14 months many children had transitioned on to new schools or middle schools that had not participated in the initial consent procedure. These new schools could not be held to the agreements made by officials at previous schools. With regard to staffing limitations, all sites experienced some difficulty completing data collection with the personnel that were available, given that the sociometric procedures involved multiple steps: distribution of consent forms, collection and tracking of consent forms, and actual administration of the sociometric measures. For children in Grades 1 and 2, administration had to be conducted in individual sessions, further increasing the time demands. As a result, sites were unable to complete the data collection on all children with their limited resources. However, reasons for nonparticipation were generally unrelated to patient characteristics, as we demonstrate shortly.

Participants

A total of 2,517 children (1,997 boys, 520 girls) participated in this study; 285 (226 boys, 59 girls) were MTA participants with ADHD who were 7.0 to 9.9 years of age at entry into the MTA. $2^{\text {ii }}$ The remaining children were same-sex classmates of the MTA children who provided sociometric assessments only. (Data were not collected from opposite-sex peers.) Classmates did not participate in treatment, nor were they evaluated by MTA staff; therefore, their precise ages are not known, although they can be assumed to be closely related to those of the MTA participants. The distribution of MTA participants across the treatment groups was as follows: community care $=66$, medication management $=68$, behavior therapy $=70$, combined treatment $=81$.

Because not all children with ADHD from the MTA participated in the peer sociometrics, we compared descriptive characteristics of those children with and without sociometric data to ensure that no selection biases affected participation in the sociometric procedures. Comparisons were made on pretreatment (baseline) characteristics: age; sex; ethnicity; grade; Verbal, Performance, and Full Scale scores from the Wechsler Intelligence Scale for Children-Third Edition (Wechsler, 1991); Reading, Math, and Spelling scores from the Wechsler Individual Achievement Test (Wechsler, 1992); parent and teacher behavioral ratings on the Swanson, Nolan, and Pelham, version IV (SNAP-IV; Swanson, 1992); parental employment status; family receipt of public assistance; family income; and parental marital status. Using a liberal $p$ value of .05 for each individual comparison, only ethnicity differentiated among sociometric participants and nonparticipants at the14-month assessment point. The direction of this difference indicated that White children were overrepresented among participants. Specifically, percentages of children of White, Black, and “other” ethnicity were 68\%, 18\%, and $15 \%$ among participants, respectively, and 54\%, 22\%, and 24\% among nonparticipants.

\section{Informed Consent}

In this study, at all but one site, an active parental consent procedure was employed prior to participation in the peer sociometrics. (Parental consent was not obtained at the remaining site due to a decision made by local school officials that parental consent was not required.) Rates of participation for peers of the same sex as the MTA target child were calculated for 257 of the 285 classrooms involved. (Data on participation rates were not available for the remaining 28 classrooms.) The mean same-sex participation rate was $71 \%$, the median rate was $71 \%$, and the 
modal rate was 100\%. Crick and Ladd (1989) estimated (using computer simulation technology) that only $3 \%$ of rejected children are misclassified with $70 \%$ participation. Hence, our participation rates appear adequate.

Procedure and Measures Utilized

Sociometrics were administered individually for children in Grades 1 or 2 and for any classrooms in Grades 3 or higher whose teacher determined that 3 or more students would have difficulty reading the forms. Otherwise, sociometrics were group-administered with instructions (but not children's names) read aloud; research assistants provided help individually as needed.

Positive nominations.

Older children were given a list of same-sex participating classmates and were first asked to circle the names of all children on the list who were their "best friends in the class." Children were then asked to number up to three of the classmates they had selected to indicate their "very, very best friend in the class," their "next best friend in the class," and their "third best friend in the class.”

Younger children followed a similar procedure with the exception that the classmates' names appeared on individual name cards instead of a list. Before beginning, each name card was reviewed to make sure the child could read each name. Children made their selections in individual sessions during a two-step procedure similar to the one described previously by picking up or pointing to the name cards.

\section{Negative nominations.}

Older children were given another copy of the class list and were asked to circle the names of the same-sex classmates that they "DO NOT want to be friends with." They were allowed to choose as many or as few as they wished and were explicitly instructed not to number the negative choices (for ethical reasons). Younger children again used name cards, and selections were made by picking up or pointing to the cards.

\section{Rating scale sociometric.}

Each child was asked to rate each other child using a 5-point rating scale ranging from 1 (really like) to 5 (really do not like). To make certain that the meaning of the scale was clear, the positive end of the scale was anchored with a "smiley face" and the negative end with a "frowney face." This scale was administered in paper-and-pencil form to older children in the sample.

For younger children, classmates' names appeared on individual name cards that were presented one at a time to be rated. A large visual aid depicting the numbers on the scale, together with explanatory faces (smiley, neutral, and frowney) was used.

Scoring Procedures

\section{Positive and negative nominations.}

The numbers of positive and negative nominations that each child received from his or her peers were calculated to reflect the extent to which children were accepted or rejected by the peer group, respectively. To put classrooms with differing numbers of nominators into the same metric, we converted raw sums to $z$ scores, computed separately within each classroom. Each child's acceptance and rejection $z$ scores were then summed to reflect his or her total social impact (acceptance + rejection), and rejection was subtracted from acceptance to index social 
preference (acceptance - rejection). Social impact and social preference were then standardized within class and used as dependent variables.

Average received liking rating.

The mean liking rating received from classmates was computed and analyzed as a second measure of social preference within the peer group. The correlation between average received liking and social preference was -.79, with the negative correlation resulting because lower scores indicated greater liking on the rating scale, whereas the reverse was true for social preference. Both measures are reported to facilitate comparison of our results with those of prior investigators who used only one or the other of these measures.

Dyadic best friendship.

Dyadic best friendship is a construct reflecting reciprocated, intensely positive regard between two individuals. For dyadic best friendship scores to accurately reflect close relationships, we often employ only the top one or two best friendship selections in indexing dyadic best friendship (e.g., Bukowski, Hoza, \& Newcomb, 1994). Using this approach, dyadic best friendship scores could range from 0 to 2 .

Level of imbalance.

As noted in our prior work (Hoza et al., in press), there has been a relative neglect in the literature of what we call level of imbalance or "how the child views the members of his/her peer group relative to how the members of the peer group view the child" (p. 5). Yet, children with ADHD have been described as "out of synchrony with ongoing events, ... insensitive to others' needs and unresponsive to cues and feedback” (Whalen \& Henker, 1992, p. 397). In light of this, level of imbalance may be important to examine in understanding peer problems in children with ADHD, as it appears to reflect the extent to which children are "tuned in" to those around them. Therefore, positive imbalance and negative imbalance scores were computed by comparing the score a child assigned to each same-sex classmate on the 5-point liking rating scale to the score he or she received from each classmate. If the child received a better rating (i.e., lowerindicating more liking) than he or she gave, the absolute value of the difference was added to that child's positive imbalance total; if the child received a worse rating (i.e., higher-indicating less liking), than he or she gave, the absolute value of the difference was added to the child's negative imbalance total. Imbalance scores were then standardized within class, to produce comparable scores across classes of differing size. $3^{\text {iii }}$

\section{Nominated and nominating peers.}

Consistent with our prior work (Hoza et al., in press), we considered the valence within the larger peer group of both nominated peers (i.e., peers selected by each child as a friend or nonfriend) and nominating peers (i.e., those children who selected each child as a friend or nonfriend). In considering positively nominated peers, we identified classmates selected by each child as a first or second-best friend and computed the average social preference, social impact, and liking scores for this chosen subgroup. We called these variables positively nominated peers' social preference, social impact, and liking. We also identified classmates who selected each child as a first- or second-best friend on the positive nomination procedure and computed their average social preference, social impact, and liking scores. These variables are called positively nominating peers'social preference, social impact, and liking. Prior work indicates that including 
only the top two choices produces variables with greater variance (Hoza et al., in press; Mrug, Hoza,\&Bukowski, 2004), and we therefore followed this precedent.

For the subgroup of children who selected or were selected by each child on the negative nomination, a similar procedure was followed with the exception that unlimited-choice negative nominations were used to produce the nominated and nominating peers' scores (we did not have limited nominations for the negative criterion). Because these scores computed from unlimitedchoice negative nominations were more similar in their variances to the positive nominations with only the two top choices considered (in contrast to all positive nomination choices), we believe this to be an acceptable approach. These variables are called negatively nominated peers' social preference, social impact, and liking and negatively nominating peers' social preference, social impact, and liking.

\section{Results}

Preliminary Analyses

Because sociometric data could not be obtained for the full sample, preliminary analyses were first conducted to appraise whether the children in the four treatment groups for whom we had data were comparable on demographic and baseline behavioral measures. Comparisons were made on age; sex; ethnicity; grade; Verbal, Performance, and Full Scale scores from the Wechsler Intelligence Scale for Children-Third Edition (Wechsler, 1991); Reading, Math, and Spelling scores from the Wechsler Individual Achievement Test (Wechsler, 1992); parent and teacher behavioral ratings on the Swanson, Nolan, and Pelham, version IV (SNAP-IV; Swanson, 1992); parental employment status; family receipt of public assistance; family income; and parental marital status. No differences were found on any of these baseline variables across the four treatment groups (all $p$ values $>$.05).

Primary Analyses

The primary analyses examined how medication management, behavior therapy, and combined treatment groups performed in comparison to one another and relative to community standard treatments in terms of alleviating the peer problems of children with ADHD. However, results to date on other (i.e., nonsociometric) outcome variables at 14 months suggest that there is little difference between the two groups involving the MTA medication algorithm (combined treatment, medication management), and no difference between the two groups not involving the MTA medication algorithm (behavior therapy, community care).Yet, there were both clinically and statistically significant differences between the two groups involving the MTA medication algorithm and the two not (MTA Cooperative Group, 1999a; Swanson et al., 2001) regarding ADHD and oppositional symptomatology. Hence, we tested for the following orthogonal contrasts: Medication Management + Combined versus Behavior Therapy + Community Care; Medication Management versus Combined; Behavior Therapy versus Community Care. We report effect sizes (Cohen's $d$ ) for all contrasts.

Differences were assessed with one-way analyses of variance (ANOVAs) conducted with the 18 dependent variables listed first in Table 1, followed by the planned orthogonal contrasts. Of the 18 ANOVAs, only two analyses indicated a significant effect of treatment group (both at $p<.05)$. The orthogonal contrasts showed that children in the two medication groups obtained more positive (i.e., lower) liking ratings from their peers (Cohen's $d=-.28$ ) and were chosen on the positive nomination by peers with higher impact scores (Cohen's $d=.47$ ). The remaining effects were nonsignificant. The effect sizes for the contrasts for all dependent variables are 
summarized in Table 1. Although two other specific contrasts were statistically significant, we do not interpret these because the overall ANOVAs in each case did not reach significance.

\section{Post Hoc Analyses}

\section{Normalization analyses}

Of the 18 primary comparisons described previously for the peer-assessed variables, only two yielded significant results. This rather limited evidence of differences among the treatment groups could result from either (a) a general lack of improvement among the MTA groups in the peer relationships domain or (b) a similar degree of improvement in the MTA treatment groups. Therefore, we performed follow-up analyses comparing each MTA participant in the four treatment groups with a randomly chosen classmate. These analyses were conducted as repeatedmeasures ANOVAs, using the 18 dependent variables, with two levels of clinical status (MTA participant vs. randomly chosen classmate) as the within-subject variable and the four treatment groups as the between-subjects factor. These analyses revealed significant differences between the MTA participants and the randomly chosen classmates on nine variables (see Table 2). Compared to their randomly chosen classmates, the MTA participants received lower social preference scores, were more disliked, had fewer dyadic friendships, and had less positive imbalance and greater negative imbalance. They also negatively nominated peers who were higher on social preference and better liked, and were chosen on the negative nomination by more popular peers. The interaction between clinical status and treatment group was significant for only one variable, the social preference of negatively nominating peers. An examination of the means, however, indicated that this effect was due entirely to differences among the classmates across the four treatment groups and thus did not reflect treatment effects. Specifically, means for the children in the four treatment groups (community care: .08; medication management: -.09; combined treatment: -.08; behavioral therapy: -.05) fell within a very narrow range, whereas means for their randomly chosen classmates were much more disparate (community care: -.27 ; medication management: -.05 ; combined treatment: -.30; behavioral therapy: -.72), suggesting that this interaction was due to random variation within the groups of classmates, as opposed to differences among the treatment groups. These results, as well as the means and effect sizes for the differences between MTA participants and their classmates within each treatment group, are summarized in Table 2 . The follow-up analyses thus confirmed the general lack of differences among the four treatment groups that were revealed in the primary analyses. In addition, they showed that children with ADHD still experienced significant peer problems at the end of treatment as compared to their classmates, regardless of the treatment they received.

\begin{tabular}{llcc}
\hline & \multicolumn{2}{c}{ Effect Sizes } \\
\cline { 2 - 4 } & $\begin{array}{l}\text { Med Mgt + Comb Versus Beh } \\
+ \text { CC }\end{array}$ & $\begin{array}{c}\text { Comb Versus Med } \\
\text { Mgt }\end{array}$ & $\begin{array}{c}\text { Beh versus } \\
\text { CC }\end{array}$ \\
\hline Social preference & .17 & -.21 & -.09 \\
Social impact & -.14 & .10 & -.10 \\
Average liking (,b lower is better) & $-.28^{*}$ & .04 & .27 \\
Dyadic best friendship & .05 & .01 & -.16 \\
Positive imbalance & .07 & -.06 & .24 \\
Negative imbalance & -.08 & .09 & .15 \\
Positively nominated peers' preference & .10 & .17 & .02
\end{tabular}




\begin{tabular}{|c|c|c|c|}
\hline Positively nominated peers' impact & .06 & -.32 & .05 \\
\hline Positively nominated peers' liking ${ }^{\mathrm{a}}$ & -.24 & -.16 & .00 \\
\hline $\begin{array}{l}\text { Negatively nominated peers’ } \\
\text { preference }\end{array}$ & $-.32 *$ & .19 & .14 \\
\hline Negatively nominated peers' impact & .03 & $.54^{*}$ & .01 \\
\hline Negatively nominated peers’ liking ${ }^{\mathrm{a}}$ & .08 & -.14 & -.01 \\
\hline $\begin{array}{l}\text { Positively nominating peers' } \\
\text { preference }\end{array}$ & .04 & .26 & -.03 \\
\hline Positively nominating peers’ impact ${ }^{\mathrm{b}}$ & $.47 * *$ & -.22 & .11 \\
\hline Positively nominating peers’ liking ${ }^{\mathrm{a}}$ & -.06 & -.26 & .08 \\
\hline $\begin{array}{l}\text { Negatively nominating peers’ } \\
\text { preference }\end{array}$ & -.03 & .03 & .01 \\
\hline Negatively nominating peers' impact & -.02 & -.14 & .16 \\
\hline Negatively nominating peers' liking ${ }^{\mathrm{a}}$ & -.18 & -.11 & .07 \\
\hline Social Skills Rating System-Teacher & $.26^{*}$ & .07 & .23 \\
\hline Social Skills Rating System-Parent ${ }^{\mathrm{C}}$ & $.48 * * *$ & .20 & .04 \\
\hline
\end{tabular}

Note: $N$ ranges from 41 to 81 for the four treatment groups. CC = Community care; Beh = behavioral; Med Mgt = medication management; Comb = Combined.

${ }^{\mathrm{a}}$ Lower scores are better. ${ }^{\mathrm{b}}$ Overall significant effect of treatment group at $p<.05$.

${ }^{\mathrm{C}}$ Overall significant effect of treatment group at $p<.01 ;{ }^{*} p<.05$;

$* * p<.01 ; * * * p<.001$.

Table 1. Effect Sizes for Planned Contrasts

\begin{tabular}{|c|c|c|c|c|c|c|}
\hline & \multicolumn{2}{|c|}{ ADHD } & \multicolumn{2}{|c|}{ Classmates } & \multirow[b]{2}{*}{ Effect Size } & \multirow[b]{2}{*}{$\mathrm{N}$} \\
\hline & $M$ & SD & $\mathrm{M}$ & SD & & \\
\hline \multicolumn{7}{|l|}{ Social Preference ${ }^{a}$} \\
\hline Community Care & -.80 & 1.09 & .10 & .91 & -.90 & 66 \\
\hline Medical Mgt & -.52 & 1.20 & -.04 & .91 & -.45 & 68 \\
\hline Combined & -.76 & 1.06 & .11 & .90 & -.88 & 81 \\
\hline Behavioral & -.90 & 1.22 & .24 & .98 & -1.03 & 70 \\
\hline \multicolumn{7}{|l|}{ Social Impact } \\
\hline Community Care & .27 & .96 & .28 & .92 & -.01 & 66 \\
\hline Medical Mgt & .05 & 1.01 & .03 & .99 & .02 & 68 \\
\hline Combined & .15 & .91 & -.15 & 1.04 & .31 & 81 \\
\hline Behavioral & .18 & .93 & .06 & 1.13 & .12 & 70 \\
\hline \multicolumn{7}{|l|}{ Average Liking ${ }^{\mathrm{a}, \mathrm{b}}$} \\
\hline Community Care & 2.98 & .87 & 2.27 & .75 & .87 & 66 \\
\hline Medical Mgt & 2.84 & .91 & 2.38 & .76 & .55 & 68 \\
\hline Combined & 2.88 & .90 & 2.16 & .67 & .91 & 81 \\
\hline Behavioral & 3.24 & 1.04 & 2.30 & .78 & 1.02 & 70 \\
\hline
\end{tabular}


Dyadic Friendship ${ }^{\mathrm{a}}$

Community Care

Medical Mgt

Combined

Behavioral

Positive Imbalance ${ }^{\text {a }}$

Community Care

Medical Mgt

Combined

Behavioral

Negative Imbalance ${ }^{\text {a }}$

Community Care

Medical Mgt

Combined

Behavioral

Positively Nominated Peers’ Preference

Community Care

Medical Mgt

Combined

Behavioral

Positively Nominated Peers' Impact

Community Care

Medical Mgt

Combined

Behavioral

Positively Nominated Peers' Liking ${ }^{\mathrm{b}}$

Community Care

Medical Mgt

Combined

Behavioral

Negatively Nominated Peers'

Community Care

Medical Mgt

Combined

Behavioral

Negatively Nominated Peers’ Impact

$\begin{array}{lccccc}.74 & .83 & 1.00 & .79 & -.32 & 62 \\ .68 & .79 & 1.03 & .80 & -.44 & 66 \\ .73 & .80 & 1.03 & .79 & -.38 & 78 \\ .62 & .72 & 1.08 & .80 & -.60 & 65 \\ & & & & & \\ -.67 & .62 & .28 & .90 & -1.23 & 62 \\ -.43 & 1.00 & .04 & .88 & -.50 & 66 \\ -.48 & .90 & -.09 & .93 & -.43 & 78 \\ -.40 & 1.04 & .10 & .95 & -.50 & 65 \\ & & & & & \\ .70 & 1.07 & -.10 & .82 & .84 & 62 \\ .62 & 1.11 & -.15 & .86 & .78 & 66 \\ .70 & 1.03 & -.14 & .81 & .91 & 78 \\ .82 & 1.07 & -.19 & .85 & 1.05 & 65\end{array}$

$\begin{array}{llllll}.50 & .45 & .51 & .53 & -.02 & 57\end{array}$

$\begin{array}{llllll}.50 & .53 & .55 & .52 & -.10 & 60\end{array}$

$\begin{array}{llllll}.59 & .45 & .55 & .53 & .08 & 76\end{array}$

$\begin{array}{llllll}.51 & .62 & .51 & .50 & .00 & 60\end{array}$

$\begin{array}{llllll}.11 & .67 & .15 & .60 & -.06 & 57\end{array}$

$\begin{array}{llllll}.25 & .69 & .28 & .66 & -.04 & 60\end{array}$

$\begin{array}{llllll}.05 & .64 & .33 & .58 & -.46 & 76\end{array}$

$\begin{array}{llllll}.11 & .63 & .07 & .57 & .07 & 60\end{array}$

$\begin{array}{llllll}2.01 & .47 & 2.01 & .51 & .00 & 57\end{array}$

$\begin{array}{llllll}1.92 & .45 & 1.93 & .43 & -.02 & 60\end{array}$

$\begin{array}{llllll}1.86 & .41 & 1.87 & .48 & -.02 & 76\end{array}$

$\begin{array}{llllll}2.00 & .51 & 2.10 & .49 & -.20 & 60\end{array}$

$\begin{array}{llllll}-.58 & .75 & -1.26 & .74 & .91 & 36\end{array}$

$\begin{array}{llllll}-1.04 & .81 & -1.14 & .73 & .13 & 35\end{array}$

$\begin{array}{llllll}-.84 & .79 & -1.23 & .60 & .56 & 39\end{array}$

$\begin{array}{llllll}-.64 & .58 & -1.21 & .69 & .89 & 46\end{array}$


Community Care

Medical Mgt

Combined

Behavioral

Negatively Nominated Peers’ Liking ${ }^{\text {a,b }}$

Community Care

Medical Mgt

Combined

Behavioral

Positively Nominating Peers'

Community Care

Medical Mgt

Combined

Behavioral

Positively Nominating Peers' Impact

Community Care

Medical Mgt

Combined

Behavioral

Positively Nominating Peers' Liking ${ }^{\mathrm{b}}$

Community Care

Medical Mgt

Combined

Behavioral

Negatively Nominating Peers'

Community Care

Medical Mgt

Combined

Behavioral

Negatively Nominating Peers' Impact

Community Care

Medical Mgt

Combined

Behavioral

Negatively Nominating Peers’ Liking

Community Care

\section{.20}

.18

.51

.27

2.95

3.24

3.13

3.08

.79

3.46

.72

$-.67$

$-.26$

36

$-.22 \quad 35$

$.46 \quad 39$

$-.13$

46

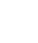

$\begin{array}{llllll}.02 & .77 & .03 & .89 & -.01 & 35 \\ .03 & .90 & .24 & .61 & -.27 & 31 \\ .08 & .70 & .39 & .57 & -.49 & 40 \\ .01 & .85 & .05 & .63 & -.05 & 35\end{array}$

$\begin{array}{lll}-.38 & .77 \quad-.05\end{array}$

.77

$-.43$

35

$\begin{array}{lll}.23 & .76 & -.01\end{array}$

.61

.35

31

$-.02 \quad .68 \quad .06$

.53

$-.13$

40

$-.36$

.78

$-.14$

.67

$-.30$

35

$\begin{array}{llllll}2.36 & .64 & 2.31 & .67 & .08 & 45\end{array}$

$\begin{array}{llllll}2.39 & .64 & 2.34 & .53 & .09 & 47\end{array}$

2.23

.50

2.11

.50

.24

49

2.39

.65

2.32

.54

.12

41

$\begin{array}{llllll}.08 & .79 & -.27 & .93 & .41 & 40\end{array}$

$\begin{array}{llllll}-.09 & .79 & -.05 & .87 & -.05 & 43\end{array}$

$\begin{array}{llllll}-.08 & .55 & -.30 & .80 & .32 & 39\end{array}$

$\begin{array}{llllll}-.05 & .73 & -.72 & .85 & .85 & 39\end{array}$

$\begin{array}{llllll}-.07 & .57 & .14 & .81 & -.30 & 40\end{array}$

$\begin{array}{llllll}-.04 & .49 & .05 & .62 & -.16 & 43\end{array}$

$\begin{array}{llllll}-.29 & .76 & -.18 & .78 & -.14 & 39\end{array}$

$\begin{array}{llllll}-.03 & .40 & -.05 & .73 & .03 & 39\end{array}$

$\begin{array}{llllll}2.41 & .67 & 2.57 & .76 & -.22 & 40\end{array}$ 


\begin{tabular}{lllllll} 
Medical Mgt & 2.47 & .66 & 2.55 & .77 & -.11 & 43 \\
Combined & 2.42 & .49 & 2.62 & .66 & -.34 & 39 \\
Behavioral & 2.65 & .66 & 3.15 & .76 & -.70 & 39 \\
\hline
\end{tabular}

Note: MTA = Multimodal Treatment Study of Children With ADHD; ADHD = attention deficit hyperactivity disorder; Mgt = Management.

${ }^{\mathrm{a}}$ The effect of clinical status was significant at $p<.001 .{ }^{\mathrm{b}}$ Lower scores are better. ${ }^{\mathrm{c}}$ The interaction between clinical status and treatment groupwas significant at $p<.05$

Table 2. Comparisons of MTA Participants With Randomly Chosen Classmates Within Treatment Group

Parent- and teacher-rated social skills analyses.

One possible explanation for our limited findings might be insufficient power to detect differences given our reduced group sizes relative to the full MTA sample. To reduce this concern, using this partial sample, we also conducted ANOVAs with orthogonal contrasts for the parent and teacher social skills subscale from the Social Skills Rating System (SSRS; Gresham \& Elliott, 1989)—a social outcome measure from the primary MTA analyses that yielded a significant effect (MTA Cooperative Group, 1999a). Although our analysis strategy differed somewhat from the main MTA analyses in terms of our follow-up tests - that is, we used three orthogonal contrasts rather than the six planned comparisons reported in the initial outcomes article (MTA Cooperative Group, 1999a)—we reasoned that we ought to be able to replicate significant effects for the SSRS if our power is sufficient. As the bottom of Table 1 indicates, we obtained significant results on the parent-rated SSRS for the medication algorithm comparison (Medication Management + Combined Treatment vs. Behavioral Therapy + Community Care) and also for the teacher-rated SSRS for this same contrast (although the overall ANOVA did not reach significance for teacher ratings). These findings are similar to those reported with the full sample, within which the teacher-rated social skills score yielded significant results and findings for parent-rated social skills were only marginally significant.

\section{Discussion}

A widely known fact in the field of academic research is that null findings are often omitted from the published literature (Rosenthal, 1979). However, we argue here that it is just as important to know when intervention efforts have been limited in their successfulness. In comparing the treatment groups from the MTA, we were able to demonstrate little evidence of superiority of any of the treatments in terms of the peer-assessed variables studied, as only two significant contrasts were found among the 18 variables studied. Because we know from prior research describing the primary MTA results that all groups improved on some non-peerassessed outcomes (MTA Cooperative Group, 1999a), we also considered the possibility that all groups improved in the peer-assessed domain and that these uniform improvements across groups reduced our ability to detect differences between groups. Therefore, we conducted post hoc analyses to examine whether children from any of the four treatment groups had normalized peer relationships at the end of treatment. Specifically, we compared children from each treatment group to randomly selected classmates and found a large number of significant differences indicating ongoing peer problems and a virtual absence of meaningful Treatment 
Group $\times$ Clinical Status interactions. Hence, our conclusion is that children from all treatment groups remained impaired in their peer relationships.

The MTA represents the most intensive, long-term treatment study of children with ADHD accomplished to date. Treatments were state-of-the-art and extended over a 14-month period. Both the intensity and the duration of treatments exceeded what is normally administered in clinical practice. In fact, the MTA has been criticized on the basis that "All three treatment arms of the project involved exceptionally complex and expensive treatment algorithms - each involving an intensity and diversity of treatment services not widely available, if at all” (Barkley, 2000, p. 598). It is of clinical concern that even these high-intensity, long-term interventions had limited influence on the peer problems of the studied children. This result is particularly troublesome given the literature cited in the introduction indicating that peer problems are predictive of later negative outcomes.

The most obvious and important question to ponder is why results of such limited statistical and clinical significance were obtained for the peer-assessed outcomes. We know from the primary outcomes of the MTA (MTA Cooperative Group, 1999a) that these same treatments were effective to varying degrees in reducing ADHD symptoms, decreasing oppositional or aggressive and internalizing symptoms, and improving parent-child relationships and academic functioning. One possibility is that we had insufficient power to detect differences given that sociometric data were not obtained for all children. Even after missing data for some of the variables were taken into account, however, our analysis subgroup sizes ranged from 41 to 81 children across variables and groups, making this explanation unlikely. Nonetheless, we conducted power analyses for the eight peer variables that showed clear impairment at baseline (Hoza et al., in press), reasoning that these areas would be most likely to show treatment effects. Power analyses for six of the eight variables indicated that our power was .94 to detect moderatesized effects, given our four groups and the number of participants with valid data on these variables. Further, with few exceptions, our planned contrast effect sizes were uniformly small, making it unlikely that a lack of statistical power was the main culprit herein. Nonetheless, to further reduce this concern, we conducted the same orthogonal comparisons using the parentand teacher-rated social skills subscale from the SSRS-a social outcome measure from the primary MTA analyses that yielded significant effects - in this delimited sociometric sample. We demonstrated significant effects on the SSRS that were similar to those obtained with the full sample, rendering unlikely any explanation pertaining to lack of power for our sociometric variables.

Our difficulty demonstrating effects of treatment using the peer sociometric measures, whereas such effects were found using the parent- and teacher-rated SSRS, highlight the distinctiveness of adult reports of social functioning versus the perspectives of peers. Indeed, in our sample, the correlation between the peer-assessed variables and the SSRS variables only ranged from .01 to .27 in magnitude, suggesting low to modest overlap. These findings suggest that adult reports of children's social functioning and peer-assessed measures are not useful proxies for one another. Second, given the long-term predictive validity of peer-assessed variables for later outcomes (see review by Rubin et al., 1998), whenever feasible, peer-report measures should be incorporated as outcome variables into treatment studies. Although this inclusion may require greater effort and expense than more traditionally employed parent and teacher reports of symptoms and social functioning, the ability to change peer status is likely to be a much more stringent measure of success than improvement in adult-perceived functioning. 
To place these results in the proper context of the broader literature on peer interventions, we need to point out that others have reported similarly disappointing findings for non-ADHD samples of children. For example, one recent review examining social skills training as a treatment for aggressive children noted "that peers may often be resistant to changing their feelings toward a child that they dislike, even when positive change has occurred” (Nangle et al., 2002, p. 191). Therefore, we believe the implication of our results is not that social skills training, behavior therapy, and the other peer interventions we employed are not worthwhilebut rather, they are clearly not sufficient. Even in combination with medication, our intensive interventions failed to normalize the peer-assessed outcomes of the treated children even though other outcome variables related to social performance revealed that behavior had changed.

Our results reinforce the efforts of peer researchers and social skills interventionists who have already begun to look beyond the rejected child and the immediate treatment context in explaining the stubborn persistence of peer problems. These efforts have focused on the peer group as a factor impeding change in two ways. First, Hymel, Wagner, and Butler (1990) argued that reputations within a peer group persist, even after behavior has changed, and that these reputations influence perceptions of the peer group toward an individual child, as well as their reactions to the child. For example, whereas peers are likely to give a liked peer the "benefit of the doubt" when a social transgression occurs, no such leeway is extended to disliked peers (Hymel, 1986). These reputational factors make it difficult, at best, for a rejected child who has undergone treatment such as in the MTA to gain any ground when returning to the same natural peer group.

Relevant to this perspective, Harris, Milich, Corbitt, Hoover, and Brady (1992) conducted a study involving an interaction task that crossed expectancy for a partner with ADHD and actual ADHD status of the interaction partner in dyads of previously unacquainted children. Their results demonstrated that children who expected to interact with a partner with ADHD were significantly less friendly during the actual interaction and talked less (a marginal finding), regardless of the actual status of the partner. In other words, expecting to have a partner with ADHD seemingly created less positive interactions even when the partner's behavior did not warrant it. In addition, normal children described as "ADHD” had a more negative experience during the task than normal boys not described in this manner. The authors concluded "that a stigmatizing label may lead to a self-fulfulling prophecy with respect to peer rejection” (p. 49). Similarly, even though the behavior of children treated in the MTA improved with treatment, the lingering negative expectancy of peers may have maintained their peer rejection. Future work should examine the factors influencing the malleability of these negative expectancies and labels, to derive effective strategies for altering them.

Along similar lines, for social skills to be employed in the natural setting once they are learned, these skills must be reinforced by the peers in that setting. Early work by Nangle, Erdley, and Gold (1996) indicated that rejected, disruptive children tend to associate at school with peers who are similarly disruptive; these peers are not likely to provide much reinforcement for prosocial behaviors and, in fact, may punish them. Although a later study by the same research group (Nangle, Erdley, Zeff, Stanchfield, \& Gold, 2004) only partially replicated this earlier finding (i.e., the tendency to associate with others similar to oneself was found for girls but not boys), both studies by Nangle and colleagues $(1996,2004)$ found that in terms of disliking, more rejected, disruptive children tended to be disliked by more popular, prosocial children-those most likely to display adaptive social skills. The end result may be that rejected disruptive children rarely associate with, or receive reinforcement from, children most likely to 
value the social skills they have been taught. Importantly, we found support for the conclusion that higher status peers were more rejecting of children with ADHD. Specifically, relative to classmates, children with ADHD were chosen on the negative nomination by children of higher preference and greater liking within the peer group, even after 14 months of treatment. This finding does, in fact, suggest that treated children with ADHD may have difficulty obtaining the approval of influential peers and hence securing support or reinforcement from them in response to new skills learned in treatment.

Several caveats about our findings are needed. The greatest limitation of this work is that we cannot evaluate change in these peer-assessed variables over time. Specifically, the subsamples of children for whom we have sociometric data at each time point are not consistent - for example, the individual children in the subsample changes from baseline to 14 months. It is possible that the children with ADHD did improve somewhat in their peer functioning from an even more dismal starting point. Comparisons of effect sizes at baseline (see Hoza et al., in press) to those obtained here, however, suggest that any such changes were not dramatic.

Also, as mentioned when discussing our preliminary analyses, ethnic minority children were underrepresented among children in our sample for whom we were able to obtain peer data. Although the reasons for this underrepresentation are not clear, this result should give us pause before attempting to generalize these results to minority children. Further work should examine peer difficulties in minority samples to allow more definitive conclusions.

In summary, we found little evidence of superiority of any of the MTA treatments for the peer-assessed outcomes studied, and post hoc analyses indicated that children from all groups remained significantly impaired in their peer relationships even after 14 months of treatment. Given the well-established findings of the long-term predictive utility of peer difficulties for later serious forms of maladjustment, developing more effective interventions for peer problems in children with ADHD should be given high priority as a significant public health concern.

\section{Acknowledgements}

Data analysis and article preparation was supported by Grant R01 MH62583 from the National Institute of Mental Health to Betsy Hoza.

The Multimodal Treatment Study of Children With Attention Deficit Hyperactivity Disorder is a cooperative treatment study performed by six independent research teams in collaboration with the staff of the Division of Clinical and Treatment Research of the National Institute of Mental Health, Rockville, Maryland, and the Office of Special Education Programs of the U.S. Department of Education. The National Institute of Mental Health principal collaborators are Peter S. Jensen, L. Eugene Arnold, John E. Richters, Joanne B. Severe, Donald Vereen, and Benedetto Vitiello. Principal investigators and coinvestigators from the six sites are as follows: University of California at Berkeley and San Francisco (UO1 MH50461): Stephen P. Hinshaw, Glen R. Elliott; Duke University Medical Center (UO1 MH50447): C. Keith Conners, Karen C. Wells, John S. March; University of California at Irvine and Los Angeles (UO1 MH50440): James M. Swanson; Dennis P. Cantwell (deceased); Timothy Wigal; Long Island Jewish Medical Center and Montreal Children’s Hospital (UO1 MH50453): Howard B. Abikoff, Lily Hechtman; NewYork State Psychiatric Institute, Columbia University, and Mount Sinai Medical Center (UO1 MH50454): Laurence L. Greenhill, Jeffrey H. Newcorn; University of Pittsburgh (UO1 MH50467): William E. Pelham, Betsy Hoza. Helena C. Kraemer (of Stanford University) is the statistical and design consultant. The Office of Special Education Programs of the U.S. Department of Education principal collaborator is Ellen Schiller.

\section{References}

American Psychiatric Association. (1994). Diagnostic and statistical manualofmentaldisorders (4th ed.).Washington,DC:Author. 
Arnold, L. E., Abikoff, H. B., Cantwell, D. P., Conners, C. K., Elliott, G., Greenhill, L. L., et al. (1997). National Institute of Mental Health collaborative Multimodal Treatment Study of Children with ADHD (the MTA): Design challenges and choices. Archives of General Psychiatry, 54, 865-870.

Barkley, R. A. (1998). Attention-deficit hyperactivity disorder: A handbook for diagnosis and treatment (2nd ed.). New York: Guilford.

Barkley, R. A. (2000). Commentary on the Multimodal Treatment Study of Children with ADHD. Journal of Abnormal Child Psychology, 28, 595-599.

Barkley, R. A., Guevremont, D. C., Anastopoulos, A. D., DuPaul, G. J.,\&Shelton,T. L. (1993). Driving-related risks and outcomes of attention deficit hyperactivity disorder in adolescents and young adults:A3- to5-year follow-upsurvey.Pediatrics, 92,212-218.

Bierman, K. L., Miller, C. L., \& Stabb, S. D. (1987). Improving the social behavior and peer acceptance of rejected boys: Effects of social skill training with instructions and prohibitions. Journal of Consulting and Clinical Psychology, 55, 194-200.

Bukowski,W. M., Hoza, B., \& Newcomb, A. F. (1994). Using rating scale and nomination techniques to measure friendship and popularity. Journal of Social and Personal Relationships, 11, 485-488.

Crick, N. R., \& Ladd, G. W. (1989). Nominator attrition: Does it affect the accuracy of children's sociometric classifications? Merrill-Palmer Quarterly, 35, 197-207.

Cunningham, C. E., Siegel, L. S.,\&Offord, D. R. (1985). A developmental dose-response analysis of the effects of methylphenidate on the peer interactions of attention deficit disorderedboys. Journal of Child Psychology and Psychiatry, 26, 955-971.

Foster, S. L., Inderbitzen, H. M., \& Nangle, D.W. (1993). Assessing acceptance and social skills with peers in childhood: Current issues. Behavior Modification, 17, 255-286.

Greenhill, L. L., Abikoff, H. B., Arnold, L. E., Cantwell, D. P., Conners, C. K., Elliott, G., et al. (1996). Medication treatment strategies in the MTA study: Relevance to clinicians and researchers. Journal of the American Academy of Child \& Adolescent Psychiatry, 35, 1304-1313.

Gresham, F. M., \& Elliott, S. N. (1989). Social Skills Rating System—Parent, Teacher, and Child forms. Circle Pines, MN: American Guidance Systems.

Harris, M. J., Milich, R., Corbitt, E. M., Hoover, D.W., \& Brady,M. (1992). Self-fulfilling effects of stigmatizing information on children's social interactions. Journal of Personality and Social Psychology, 63, 41-50.

Hinshaw, S. P., March, J. S., Abikoff, H., Arnold, L. E., Cantwell, D. P., Conners, C. K., et al. (1997). Comprehensive assessment of childhood attention-deficit hyperactivity disorder in the context of a multisite, multimodal clinical trial. Journal of Attention Disorders, 1, 217-234.

Hoza, B., Mrug, S., Gerdes, A. C., Hinshaw, S. P., Bukowski,W. M., Gold, J. A., et al. (in press). What aspects of peer relationships are impaired in children with ADHD? Journal of Consulting and Clinical Psychology.

Hoza, B., Mrug, S., Pelham, W. E., Greiner, A. R., \& Gnagy, E. M. (2003). A friendship intervention for children with attention-deficit/hyperactivity disorder: Preliminary findings. Journal of Attention Disorders, 6, 8798.

Hymel, S. (1986). Interpretations of peer behavior: Affective bias in childhood and adolescence. Child Development, $57,431-445$.

Hymel, S., Wagner, E., \& Butler, L. J. (1990). Reputational bias: View from the peer group. In S. R. Asher \& J. D. Coie (Eds.), Peer rejection in childhood (pp. 156-186). New York: Cambridge University Press.

Klein R. G., Abikoff, H., Hechtman L., \& Weiss, G. (2004). Design and rationale of controlled study of long-term methylphenidate and multimodal psychosocial treatment in children with ADHD. Journal of the American Academy of Child \& Adolescent Psychiatry, 43, 792-801.

Landau, S., \& Moore, L. A. (1991). Social skill deficits in children with attention-deficit hyperactivity disorder. School Psychology Review, 20, 235-251.

Mrug, S., Hoza, B., \& Bukowski, W. M. (2004). Choosing or being chosen by aggressive-disruptive peers: Do they contribute to children's externalizing and internalizing problems? Journal of Abnormal Child Psychology, 32, 53-65.

Mrug, S., Hoza, B., \& Gerdes, A. C. (2001). Children with attention-deficit/hyperactivity disorder: Peer relationships and peer-oriented interventions. In W. Damon (Series Ed.), D. W.

Nangle \& C. A. Erdley (Eds.), New directions for child and adolescent development: No. 91. The role of friendship in psychological adjustment (pp. 51-77). San Francisco:Jossey-Bass. 
MTA. (1999a). A 14-month randomized clinical trial of treatment strategies for attention-deficit/hyperactivity disorder. Archives of General Psychiatry, 56, 1073-1086.

MTA. (1999b). Moderators and mediators of treatment response for children with attention-deficit/hyperactivity disorder: The Multimodal Treatment Study of Children with Attention-Deficit/Hyperactivity Disorder. Archives of General Psychiatry, 56, 1088-1096.

Nangle, D. W., Erdley, C. A., Carpenter, E. M., \& Newman, J. E. (2002). Social skills training as a treatment for aggressive children and adolescents: A developmental-clinical integration. Aggression \& Violent Behavior, 7, 169-199.

Nangle, D. W., Erdley, C. A., \& Gold, J. A. (1996). A reflection on the popularity construct: The importance of who likes or dislikes a child. Behavior Therapy, 27, 337-352.

Nangle, D.W., Erdley, C. A., Zeff, K. R., Stanchfield, L. L., \& Gold, J. A. (2004). Opposites do not attract: Social status and behavioral-style concordances and discordances among children and the peers who like and dislike them. Journal of Abnormal Child Psychology, 32, 425-434.

Oden, S., \& Asher, S. R. (1977). Coaching children in social skills for friendship making. Child Development, 48, 495-506.

Parker, J. G., \& Asher, S. R. (1987). Peer relations and later personal adjustment: Are low-accepted children at risk? Psychological Bulletin, 102, 357-389.

Pelham,W. E., \& Bender, M. E. (1982). Peer relationships in hyperactive children: Description and treatment. Advances in Learning and Behavioral Disabilities, 1, 365-436.

Pelham, W. E., \& Hoza, B. (1996). Intensive treatment: A summer treatment program for children with ADHD. In E.D. Hibbs\&P. S. Jensen (Eds.), Psychosocial treatments for child and adolescent disorders: Empirically based strategies for clinical practice (pp. 311-340). Washington, DC: American Psychological Association.

Pelham, W. E., Schnedler, R. W., Bender, M. E., Nilsson, D. E., Miller, J., Budrow, M. S., et al. (1988). The combination of behavior therapy and methylphenidate in the treatment of attention deficit disorders: A therapy outcome study. In L. Bloomingdale (Ed.), Attention deficit disorder (Vol. III, pp. 29-48). New York: Pergamon.

Pfiffner, L. J., \& McBurnett, K. (1997). Social skills training with parent generalization: Treatment effects for children with attention deficit disorder. Journal of Consulting and Clinical Psychology, 65, 749-757.

Richters, J. E., Arnold, L. E., Jensen, P. S., Abikoff, H., Conners, C. K., Greenhill, L. L., et al. (1995). NIMH collaborative multisite Multimodal Treatment Study of Children with ADHD: I. Background and Rationale. Journal of the American Academy of Child and Adolescent Psychiatry, 34, 987-1000.

Rosenthal, R. (1979). The "file drawer problem" and tolerance for null results. Psychological Bulletin, 86, 638-641.

Rubin, K. H., Bukowski, W., \& Parker, J. G. (1998). Peer interactions, relationships, and groups. InW. Damon (Series Ed.)\&N. Eisenberg (Vol. Ed.), Handbook of child psychology: Vol. 3. Social, emotional, and personality development (pp. 619-700). New York: Wiley.

Satterfield, J. H., Satterfield, B. T., \& Schell, A. M. (1987). Therapeutic interventions to prevent delinquency in hyperactive boys. Journal of the American Academy of Child \& Adolescent Psychiatry, 26, 56-64.

Satterfield, J., Swanson, J., Schell, A., \& Lee, F. (1994). Prediction of antisocial behavior in attention-deficit hyperactivity disorder boys from aggressive/defiance scores. Journal of the American Academy of Child \& Adolescent Psychiatry, 33, 185-190.

Swanson, J. M. (1992). School-based assessments and interventions for ADD students. Irvine, CA: K. C. Publications.

Swanson, J. M., Arnold, L. E., Vitiello, B., Abikoff, H. B.,Wells, K. C., Pelham,W. E., et al. (2002). Response to commentary on the Multimodal Treatment Study of ADHD (MTA): Mining the meaning of the MTA. Journal of Abnormal Child Psychology, 30, 327-332.

Swanson, J. M., Kraemer, H. C., Hinshaw, S. P., Arnold, L. E., Conners, C. K., Abikoff, H. B., et al. (2001). Clinical relevance of the primary findings of the MTA: Success rates based on severity of ADHD and ODD symptoms at the end of treatment. Journal of the American Academy of Child \& Adolescent Psychiatry, 40, 168-179.

Wechsler, D. (1991). Wechsler Intelligence Scale for Children (3rd ed.). San Antonio, TX: Psychological Corporation.

Wechsler, D. (1992).Wechsler Individual Achievement Test. San Antonio, TX: Psychological Corporation.

Weiss, G.,\&Hechtman, L. T. (1993). Hyperactive children grown up (2nd ed.). New York: Guilford. 
Wells, K. C., Pelham,W. E., Kotkin, R. A., Hoza, B., Abikoff, H. B., Abramowitz, A., et al. (2000). Psychosocial treatment strategies in the MTA study: Rationale, methods, and critical issues in design and implementation. Journal of Abnormal Child Psychology, 28, 483-505.

Whalen, C. K., \& Henker, B. (1991). Social impact of stimulant treatment for hyperactive children. Journal of Learning Disabilities, 24, 231-241.

Whalen, C. K., \& Henker, B. (1992). The social profile of attention-deficit hyperactivity disorder: Five fundamental facets. Child and Adolescent Psychiatric Clinics of North America, 1, 395-410.

Whalen, C. K., Henker, B., Buhrmester, D., Hinshaw, S. P., Huber, A., \& Laski, K. (1989). Does stimulant medication improve the peer status of hyperactive children? Journal of Consulting and Clinical Psychology, 57, 545-549.

Whalen, C. K., Henker, B., Castro, J., \& Granger, D. (1987). Peer perceptions of hyperactivity and medication effects. Child Development, 58, 816-828.

Wheeler, J., \& Carlson, C. L. (1994). The social functioning of children with ADD with hyperactivity and ADD without hyperactivity: A comparison of their peer relations and social deficits. Journal of Emotional and Behavioral Disorders, 2, 2-12.

\footnotetext{
' The reasons for this were several. In the primary-outcome articles, emphasis was placed on measures for which we had complete data both at baseline and at 14 months. This was not true of the sociometric measures, because sociometrics were an optional part of the protocol at baseline. Also, at the time the 14-month articles were published, the sociometric data set had not yet been "cleaned" and made ready for analysis. This work was accomplished by Betsy Hoza through a separate grant to her, independent of the main MTA project. For these reasons, only one peer-assessed variable was included in the initial report from the MTA-average received liking rating - although in that prior report (MTA Cooperative Group, 1999a), the orthogonal contrast strategy we employ here was not utilized.

ii In actuality, a slightly larger number of children ( $n=2,582: 2,045$ boys, 537 girls) participated in the sociometric assessments. However, data from 65 children were screened out because too few (fewer than 5) children in the classroom participated to yield valid data.

iii The standardized scores (i.e., z scores) for acceptance, rejection, social impact, and social preferencewerecalculated using the descriptive sample standard deviation (the square root of the sum of squares divided by the sample size). In contrast, the $z$ scores for positive and negative imbalance were calculated via the procedures used in the SPSS software. It appears that the software algorithm uses the estimate of the population standard deviation (the square root of the sum of squares divided by the sample size minus one) when computing $z$ scores. This discrepancy is unlikely to have added anything beyond a trivial amount of "noise" in the calculations of the scores we used.
} 